OPEN ACCESS

Edited by:

Matteo Bellone,

San Raffaele Hospital

(IRCCS), Italy

Reviewed by:

Scott Rodig,

Brigham and Women's Hospital, United States

Luis De La Cruz-Merino,

Hospital Universitario

Virgen Macarena, Spain

${ }^{*}$ Correspondence:

Alexandar Tzankov alexandar.tzankov@usb.ch

Specialty section: This article was submitted to

Cancer Immunity and Immunotherapy,

a section of the journal

Frontiers in Oncology

Received: 22 December 2017

Accepted: 20 February 2018

Published: 07 March 2018

Citation:

Menter T and Tzankov A (2018)

Mechanisms of Immune Evasion

and Immune Modulation

by Lymphoma Cells.

Front. Oncol. 8:54.

doi: 10.3389/fonc.2018.00054

\section{Mechanisms of Immune Evasion and Immune Modulation by Lymphoma Cells}

\author{
Thomas Menter and Alexandar Tzankov* \\ Institute of Pathology and Medical Genetics, University Hospital of Basel, Basel, Switzerland
}

Purpose: Targeting cancer cells by modulating the immune system has become an important new therapeutic option in many different malignancies. Inhibition of CTLA4/B7 and PD1/PDL1 signaling is now also being investigated and already successfully applied to various hematologic malignancies.

Methods: A literature review of PubMed and results of our own studies were compiled in order to give a comprehensive overview on this topic.

Results: We elucidate the pathophysiological role of immunosuppressive networks in lymphomas, ranging from changes in the cellular microenvironment composition to distinct signaling pathways such as PD1/PDL1 or CTLA4/B7/CD28. The prototypical example of a lymphoma manipulating and thereby silencing the immune system is Hodgkin lymphoma. Also other lymphomas, e.g., primary mediastinal B-cell lymphoma and some Epstein-Barr virus (EBV)-driven malignancies, use analogous survival strategies, while diffuse large B-cell lymphoma of the activated B-cell type, follicular lymphoma and angioimmunoblastic T-cell lymphoma to name a few, exert further immune escape strategies each. These insights have already led to new treatment opportunities and results of the most important clinical trials based on this concept are briefly summarized. Immune checkpoint inhibition might also have severe side effects; the mechanisms of the rather un(der)recognized hematological side effects of this treatment approach are discussed.

Conclusion: Silencing the host's immune system is an important feature of various lymphomas. Achieving a better understanding of distinct pathways of interactions between lymphomas and different immunological microenvironment compounds yields substantial potential for new treatment concepts.

Keywords: CD58, CD70, Epstein-Barr virus, HLA-G, lymphoma, microenvironment, PDL1, PD1

\section{INTRODUCTION}

Next to surgery, chemotherapy and radiotherapy, immunotherapy has become a new effective strategy to treat human cancer (1). This field spans from cytokine therapy, tumor vaccines, and infusions of primed T-cells to drugs specifically targeting immune checkpoint signaling such as programmed cell death 1 (PD1/CD279) and its ligand PDL1 and the cytotoxic T-lymphocyte-associated protein 4 (CTLA4/CD152) and its ligand B7, both ligands being expressed on target- or antigen-presenting cells to inhibit T-cell activation. Though initially these treatments were designed for solid cancers, 
this concept is now readily applied in a variety of hematolymphoid neoplasms. In addition, in hematolymphoid neoplasms, another form of "immunotherapy," allogenic hematopoietic stem cell transplantation has been used for a long time already showing a tremendous improvement of patients' prognosis (2).

The history of immunotherapy reaches back more than 100 years to studies of Paul Ehrlich, and, despite obvious efficacy, its application regarding the type of treatment and its targets is still controversially discussed (3). It has been studied in various animal models with inconclusive results. While immune-deficient nude mice, which display a markedly reduced amount of T-cells, do not show an increased rate of tumors (4), specifically genetically modified mice with knock-outs of recombination activating gene 2, signal transducer and activator of transcription 1 (STAT1); or the gamma-interferon receptor show increased cancer rates even if not treated with carcinogens or crossed with animals with a cancer development stimulating mutation $(5,6)$. The reason for the lower tumor rates in nude mice is explained by a reduced, yet sustained amount of non-thymic T-cells as well as an upregulation of innate immunity. Looking at humans, patients with iatrogenic, viral or genetically caused immunodeficiency are known to have higher rates of both, virus-related cancers, such as lymphomas, squamous cell skin cancer or Kaposi sarcomas, and of non-virusrelated cancers, such as colon and lung cancer. Mechanistically, immunosurveillance of tumors, especially those, which have escaped cellular senescence (7), is mainly exerted via control of antigens presented by the cells via the major histocompatibility complex 1 (MHC1) allowing T-cells to discriminate altered, i.e., tumor cells from normal cells; CD4- and CD8-positive T-cells are the key players in controlling outgrowth of tumors (5). This mechanism puts tumor cells under pressure and leads to a selection of subclones, which have achieved the capability to evade the immune response.

In many types of tumors, cancer cells undertake considerable efforts to keep the host's immune system at bay; this involves both the tumor cells themselves, which express immunosuppressive surface proteins such as PDL1, B7, or human leukocyte antigen (HLA) G, less MHC1 or its compound $\beta$-2 microglobulin (B2M), as well the microenvironment of the tumors, which is influenced and manipulated by the tumor cells (8). Here, upregulation of regulatory T-cell subsets and subsequent anergy of cytotoxic T-cells, crosstalk with tumor growth-promoting M2 macrophages and overexpression of the immunosuppressive enzyme indoleamine 2,3-dioxygenase (IDO) play all an important role (9-11); since the role of IDO and respective therapeutic inhibition has several times been addressed and extensively reviewed, we kindly refer to some excellent publications covering this topic $(12,13)$. Furthermore, both compartments secrete various factors such as interleukins and interferons as well as tumor necrosis factor alpha or transforming growth factor beta. These factors can promote tumor cell survival on the one hand and prime the microenvironment, particularly the immune system in a pro-tumorigenic manner on the other (14).

Importantly, with the broad introduction of immunotherapy it has become obvious that not all patients respond in the same way, which is both due to tumor heterogeneity (15) as well as to individual (immuno-)genetic polymorphisms (16). In order to tackle this issue, specific biomarkers are needed to allow stratification of patients to ensure tailored treatment approaches, which might increase tumor response rates.

In this review, we mainly focus on the role of lymphoma tumor cells in the immunological crosstalk and not that of the microenvironment, as this topic will be covered by the review of Dr. $\mathrm{Xu}$ in this journal issue.

\section{HODGKIN LYMPHOMA-THE CLASSICAL PARADIGM FOR IMMUNOMODULATIVE CANCER}

Classical Hodgkin lymphoma (cHL) comprises about $20 \%$ of lymphoid malignancies. Before the development of effective chemo- and radiotherapy regimens, it was a fatal disease (17) with patients dying-apart from mechanical problems due lymphoma burden-mainly due to infections because of severe immunosuppression caused by the $\mathrm{CHL}$, exemplifying the importance of the interaction between tumor cells and the immune system. Another peculiar feature of $\mathrm{cHL}$ is the fact that the tumor cells [Hodgkinand Reed-Sternberg cells (HRS cells)] comprise less than 1\% of the lymphoma mass, and the majority of the tumor bulk is constituted by reactive or inflammatory cells in varying compositions, which depends on the cHL subtype. HRS cells both rely on their microenvironment on the one hand and need to specifically silence it on the other in order to prevent being attacked by it. This has been shown for T-cells as well as for tumor-associated macrophages (TAM). Regarding the latter, it has been shown that HRS cells induce PDL1 expression in macrophages (Figure 1A) in order to boost the immunosuppressive environment (18). Additionally, TAM and tumor-infiltrating lymphocytes express PD1, thus PD1/PDL1 blockade can both stop their immunosuppressive abilities and turn on tumor-surveilling attributes (19). It has been shown that the HRS cells are derived from germinal center B-cells as they carry clonally rearranged and somatically mutated immunoglobulin heavy- and light-chain genes $(20,21)$. HRS cells show a global downregulation of B-cell-related gene expression (22), which explains their specific immunoprofile. Genetic drivers of HRS cells are mutations in the nuclear factor kappa-light-chain enhancer of activated B cells (NF- $\mathrm{KB}$ ) pathway, of compounds of the JAK-STAT signaling and genes involved in MHC composition and expression, and communication with T-cells (23). Deciphering the mutational landscape of HRS cells has helped to get new insights into tumorigenesis of $\mathrm{cHL}$ as well as elucidating mechanisms how this tumor interacts with and, thus, manipulates the immune system $(24,25)$.

An important feature of cHL [and primary mediastinal B-cell lymphoma (PMBCL)] is gain of chromosome 9p24 (Figure 2A), which leads to an overexpression of $\operatorname{PDL} 1(25,26)$ that can also be shown in situ $(27,28)$, and seems to be of probable prognostic importance in patients treated with standard treatment regimens (25) and offers the opportunity to be specifically targeted, resulting in unprecedented response rates in otherwise hopeless cases of multiple-relapsing cHL (29). Other genes in this region encompass $J A K 2, P D L 2$, and $J M J D 2 C$, the upregulation of all of which seems to be vital for HRS cells (30), explaining why blocking PD1 


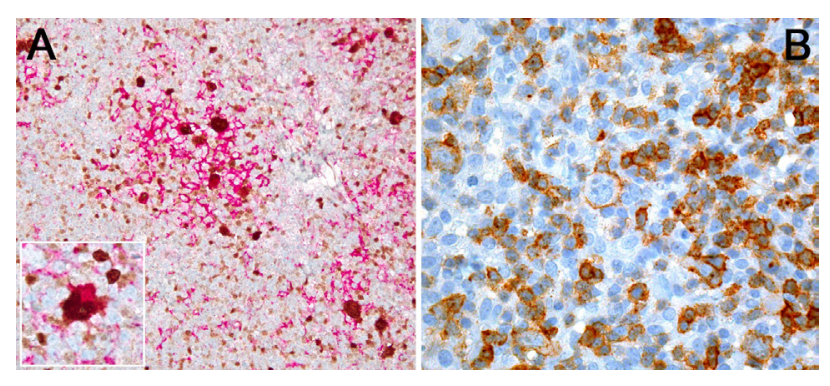

FIGURE 1 | (A) PDL1 expression study of classical Hodgkin lymphoma with PDL1 (red chromogen)-MUM1p (brown chromogen) double-staining; note that a lot of PDL1+ cells, corresponding to tumor-infiltrating macrophages, do not express MUM1p while yielding dendroid cytoplasmic projections and form "immunosuppressive microniches," in which PDL1 and MUM1p co-expressing Hodgkin- and Reed-Sternberg cells (see also inset) are scattered. (B) PD1 expression by single tumor cells (large ones) and plenty of tumor-infiltrating lymphocytes in T-cell- and histiocyte-rich B-cell lymphoma.
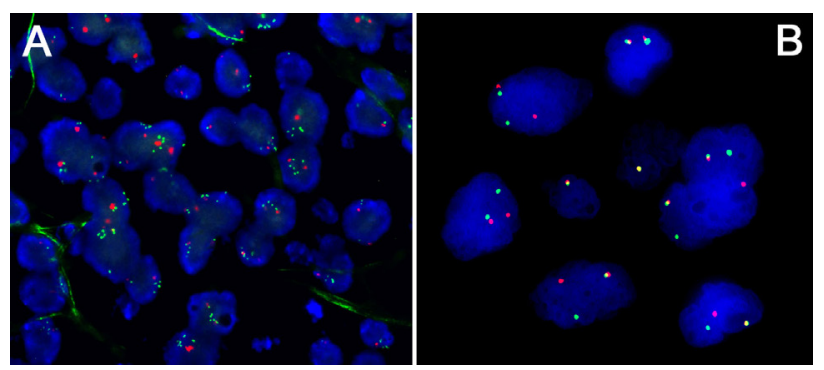

FIGURE 2 | (A) Amplification of the PDL1/JAK2 locus at 9p24 in a primary mediastinal $\mathrm{B}$-cell lymphoma (PMBCL); note multiple green FISH signals corresponding to the locus of interest compared to only 2 red centromere 9 signals/cell. (B) Rearrangement of the CIITA locus at 16p13 a PMBCL; note fused green and red signals corresponding to the non-rearranged wild-type allele and free green and red signals corresponding to the rearranged allele.

might be more effective than blocking PDL1 in cHL as the first might prevent the tumor cells also from relying on PDL2 as a substitute of blocked PDL1 (31).

Other immune escape mechanisms in CHL (and PMBCL) are deactivating translocations of CIITA (Figure 2B), the transactivator gene of MHC class II, that can be found in a subset of $\mathrm{CHL}$ (32), and downregulation of MHC class II that is reported to be also an adverse prognostic factor in affected individuals (33). The same applies to MHC class I (34), although this study could not confirm the impact of MHC class II as a prognostic factor. Regarding MHC class I, mutations in the B2M gene, which is important for MHC class I composition and function, are among the commonest in $\mathrm{cHL}$ and have been shown to be a predictor of inferior outcome independently of the 9p24 status (34).

CD58, also known as lymphocyte function-associated antigen 3 , is a glycosylated surface molecule on both B- and T-cells, which provides a stimulatory signal for $\mathrm{T}$ cells via the $\mathrm{CD} 2$ receptor. The function of CD58 in cHL is two-faced: on the one hand, it is necessary for HRS cells to communicate with CD4-positive T-cells (35), on the other hand, loss of CD58 expression due to mutations can facilitate immune escape, especially in advanced disease, when HRS cells become less dependent on the surrounding microenvironment $(36,37)$. HLA-G, a non-classical HLA molecule, plays a similar role in cHL and modulates the microenvironment to foster immunotolerance. HLA-G expression has been demonstrated both on HRS cells and the microenvironment, with high HLA-G expression on HRS cells and, conversely, low expression in the microenvironment correlating with a better outcome in one study (38).

Epstein-Barr virus (EBV) infection of HRS cells is a common feature in $30 \%$ of cHL in the Western world and $>90 \%$ especially in pediatric cases-in Central America (39). EBV infection is clonal and, thus, an early event in cHL. It immortalizes B-cells by rescuing them from apoptosis (40). EBV shows latency II state in HRS cells, with expression of the EBV-encoded genes EBV nuclear antigen 1 (EBNA1), latent membrane protein 1 (LMP1), and LMP2a. In EBV-negative cHL, the oncogenic impact of EBV seems to be substituted by mutations of genes related to the NF- $\mathrm{BB}$ pathway (e.g., C-REL) as well as several receptor tyrosine kinases (41). EBV can also upregulate PDL1 expression (42). This is primarily mediated by LMP1. LMP1 activates both the JAK/STAT pathway directly via JAK3 as well as activated protein 1 (AP1) via the microtubule-associated protein kinase (MAPK) pathway, both of which promote PDL1 gene expression (42). Interestingly, while frequencies of $9 p 24$ gains and amplifications are similar in EBV-positive and EBV-negative cHL, PDL1 expression is mostly and more selectively upregulated in EBV-positive cHL (25). EBNA1 and LMPs also directly interact with immune cells helping to create an immunosuppressive environment with enhanced amounts of regulatory T-cells (43).

Finally, HRS cells secrete a plethora of immunosuppressive soluble mediators, which is beyond the scope of this review $(44,45)$.

\section{VARIOUS MECHANISMS OF IMMUNOMODULATION IN LYMPHOMAS-A CLOSER LOOK}

In the second part of this review and after having focused on one specific lymphoma subtype, which is the prototype for immunomodulative cancer, we will have a closer look at the various mechanisms touched in the previous sections, namely, PD1/ PDL1, CTLA4/B7, HLA-G, CD58 and B2M, CD70, and CD27 as well as EBV. Beside a discussion on how these pathways exert their function and by which types of lymphomas they are used, we will also focus on interactions between them and show their synergistic and/or complementary mode of action.

\section{PD1/PDL1-The Best Studied and Most Frequently Therapeutically Used Pathway of Immune Evasion}

PD1 and its ligand PDL1 have already been discovered in the early and late 90 s, respectively $(46,47)$. A second ligand of PD1, PDL2, the expression of which is more restricted than that of PDL1, has been identified as well (48). These molecules are important tools to control T-cell activity and proliferation, and 
can both inhibit T-cells as well as stimulate immunosuppressive regulatory T-cells $(49,50)$. Another recently discovered ability is the effect of PDL1 on TAM briefly touched in the section on cHL. Gordon et al. recently showed that PDL1 blockade increases the phagocytic capability of TAM in rodent models and leads to increased survival and tumor control (19). This is an interesting and potentially also clinically relevant finding considering the bad prognostic effect of high numbers of TAM in cHL $(51,52)$, which might thus be counterbalanced by PDL1 inhibition. In contrast to CTLA4, which is discussed in the next paragraph, PD1 and its ligands exert their function in the peripheral tissue and thus do not lead to a systemic affection of the immune system, which has been nicely shown in several animal models $(53,54)$. The cytoplasmic tail of PD1 contains an immunoreceptor tyrosine-based switch motif (ITSM) and an immunoreceptor tyrosine-based inhibitory motif (ITIM), of which the ITSM is essential for the transmission of inhibitory signals [reviewed in Ref. (55)]. Upon T-cell receptor (TCR) stimulation and ligation with either PDL1 or PDL2, the ITSM and ITIM undergo phosphorylation, leading to the recruitment of the phosphatases SHP-1 and SHP-2, which in turn lead to dephosphorylation (inactivation) of the crucial T-cell signaling molecules ZAP70 and CD3 $\zeta$, and, in addition, of the phosphatidylinositol 3-kinase, which interrupts AKT and ERK signaling; even more, upon PD1 engagement by PDL1, protein tyrosine kinase- $\theta$, which is necessary for the activation of the transcription factors NFKB and AP1, is attenuated and the negative regulator of $\mathrm{T}$-cell activation, the $\mathrm{E} 3$ ubiquitin ligase CBL-b is upregulated (56-58). As a net effect, TCR-mediated activation and T-cell proliferation are impeded.

PD1/PDL1 expression in lymphomas (Figures 1A,B) has been investigated by a variety of studies with mostly consistent results $(27,28)$; it can be demonstrated in up to a third of DLBCL, mainly of the activated B-cell type (59), and in PMBCL, in other lymphoma entities it is expressed in only a low percentage of cases (27). Interestingly, in chronic lymphocytic B-cell leukemia (CLL), PDL1 expression has been described in the proliferation centers (60). PDL1 expression is observed both in the tumor microenvironment (particularly in tumor-infiltrating macrophages) and in lymphoma cells, while PD1 is primarily expressed in T-cells of the microenvironment. In T-cell- and histiocyte-rich B-cell lymphomas, PDL1 expression is seen in both T-cells and histiocytes, while the tumor cells themselves are negative for PDL1 (27). Importantly, in extranodal natural killer (NK)- and T-cell lymphoma of the nasal type, which is known to have an aggressive and mostly fatal course, PDL1 is substantially upregulated due to EBV infection of the tumor cells, and PD1 blockade has been shown to be very effective in otherwise hopeless relapse cases in a small case series (61).

As mentioned above, the genetic mechanism of PDL1 overexpression has been first elucidated in CHL consisting of alterations in chromosome 9p24.1. Similar alterations have been found in PMBCL (62) and DLBCL (63) as well as lymphomas of immuneprivileged sites such as the central nervous system and the testis (64). In addition to gene gains, PDL1 expression is inducible by LMP1 of EBV via activation of STAT- and AP1-mediated pathways. As to be expected, other causes of STAT activation also enhance PDL1 expression as seen in anaplastic lymphoma kinase-positive anaplastic large cell lymphomas (65) or in instances with active cytokine signaling (66). Another mechanism of enhancing PDL1 expression was just recently reported by Kataoka et al., who demonstrated the presence of disruption of the 3 '-untranslated region (UTR) of the $P D L 1$ gene leading to a marked increase of PDL1 that is stabilized by truncation of the $3^{\prime}$-UTR (67). Finally, at least in DLBCL, translocations of IGH, PIM1, and TP63 with the $P D L 1$ locus that lead to latter's overexpression have been described, too (63).

As in solid tumors, the direct applicability of PD1/PDL1 expression to predict therapy responsiveness and prognosis remains to be fully elucidated. Xing et al. could show that PDL1 expression in DLBCL treated with standard R-CHOP treatment is associated with a better overall survival rate, yet not with remission after first therapy, relapse- or progression-free survival (68). Several studies with small patient cohorts suggest that best responses are seen in lymphomas harboring 9p24 alterations such as lymphomas of immunoprivileged sites (69). In PMBCL, high PDL1 expression and low MUM1p expression is correlated with a better outcome than vice versa expression of these two proteins (70). A study on refractory lymphomas revealed that there is a discrepancy between PDL1 expression and amplification of the PDL1 locus, supporting the hypothesis that other mechanismsnext to gene amplifications-are involved in upregulation of PDL1 expression (71). It has also become evident that in several lymphoma types such as follicular lymphoma and CLL, adding PDL1 blockers to conventional therapy regimens shows a benefit in comparison to only very limited treatment response if given as single agents (72). For comprehensive overviews of ongoing and already finished clinical trials, we refer to several recent excellent clinically centered reviews as well as the contributions of Proff. Renner and Stenner in this issue.

\section{CTLA4-A Key Player Seemingly Not Only in T-Cell Lymphomas}

CTLA4 belongs to the superfamily of immunoglobulins (73). It is generally expressed in T-cells, and regulatory T-cells are constitutively positive (74). It shares its ligands B7-1 (CD80) and B7-2 (CD86) together with CD28, which has a function opposite to CTLA4 as it is a stimulator of TCR signaling (75). CTLA4's affinity and avidity to these ligands is greater than that of CD28 due to its bivalent binding to the $\mathrm{B} 7$ molecules (76). The main function of CTLA4 is T-cell inactivation, which is exerted by two different mechanisms: it competitively binds its ligands B7-1 and B7-2 leading to a reduced stimulatory signaling of CD28; furthermore, via its cytoplasmic tail, CTLA4 can inhibit various intracellular signaling pathways in T-cells such as NF- $\mathrm{B}, \mathrm{AP} 1$, and nuclear factor of activated T-cells (77), it can impede the cell cycle (78) and inactivate MAPK, extracellular signal-regulated kinase-1 (ERK) and c-Jun NH2 terminal kinase signaling, and thus impair interleukin 2 production (79). In contrast to PD1/ PDL1, which exert their function in the periphery, CTLA4 is acting rather early in the time course of the immune response as it is involved in priming T-cells in primary lymphoid organs (80).

CTLA4 expression is noted in a variety of T-cell lymphomas, namely, peripheral T-cell lymphomas and mycosis fungoides/ 
Sézary syndrome. Besides inducing T-cell anergy and, thus, fostering immune escape, CTLA4 has also a direct oncogenic effect: a fusion of the two opponents CTLA4 and CD28 has recently been described in a variety of T-cell lymphomas and proposed to be a major driver of lymphoma development (81). The fusion protein consisting of the extracellular and transmembrane domains of CTLA 4 and the cytosolic signaling domain of CD28 showed increased activation of intracellular MAPK and ERK signaling in cell culture experiments, confirming observations of earlier studies (82). Herrmann et al. reported CTLA4 expression in B-cell lymphomas, primarily in DLBCL (83). These lymphomas were shown to be able to exert their immunosuppressive function by binding of B7.1 and thus reducing CD28 activation on tumor-infiltrating/immunosurveillance T-cells; furthermore-as in T-cell lymphomas-CTLA4 can enhance proliferation via the STAT3 pathway, which is an important driver also in B-cell lymphomas (84). So far, CTLA4 inhibition is not commonly used in lymphoma therapy. In cHL, CTLA4 blockade has been tested in transplanted patients (85) and in combination with brentuximab, the latter still being an ongoing trial (86).

\section{HLA-G - The Unknown Member of the HLA Family}

HLA-G is a non-classical MHC class I molecule and besides the classical function of HLA proteins-presenting protein fragments on the cell surface-it exerts its function mainly by immunomodulation (87). In contrast to the classical HLA molecules, the non-classical HLA are highly conserved molecules with only few alleles. Immunomodulation by HLA-G occurs via a plethora of ways as it can interact with different receptors found on T-cells, B-cells, macrophages, dendritic cells, and NK cells (88). It interferes with proliferation and cytotoxicity as well as promotes apoptosis. Furthermore, it also inhibits chemotaxis by downregulating several chemokine surface receptors (89), hampers the function of neutrophils (90), and reduces neoangiogenesis (91). HLA-G expression has been investigated in a variety of cancers and is correlated with worse overall survival or increased risk of tumor progression and metastases in most studies (88). In lymphomas, HLA-G has been explored in only few studies so far and the results regarding the predictive role of HLA-G expression are still equivocal (92). As alluded to above, HLA-G expression has been demonstrated in $\mathrm{cHL}$ (Figures 3A,B) and its high expression in the tumor microenvironment has been correlated with an inferior response rate (38). Bielska et al. demonstrated that $H L A-G$ polymorphisms, which have a direct impact on the expression of HLA-G RNA, differ between different prognostic groups of DLBCL (93), and similar findings were reported in CLL patients (94). Both studies showed independently that especially the 14 base pair deletion polymorphism (rs66554220) in the $3^{\prime}$ UTR of HLA-G has an adverse prognostic impact.

\section{CD58 and B2M-Important Prerequisites for Immunosurveillance}

Both CD58 and B2M are important for the correct assembly of MHC class I molecules (95) and alterations thereof are another

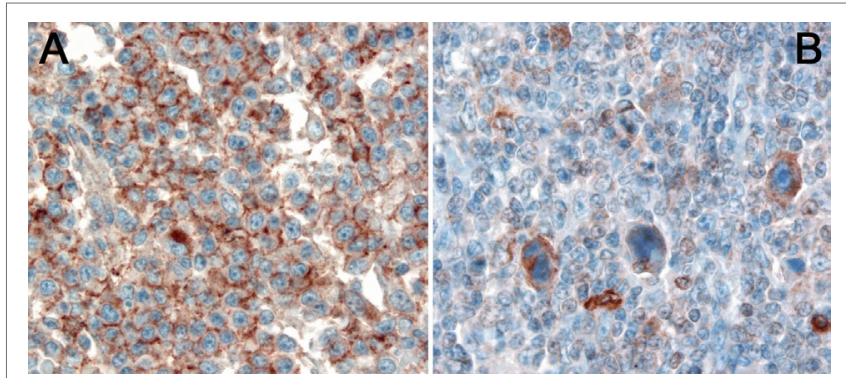

FIGURE 3 | (A) Expression of HLA-G in a diffuse large B-cell lymphoma. (B) Expression of HLA-G by Hodgkin- and Reed-Sternberg cells of classical Hodgkin lymphoma.

immune escape mechanism of tumors (96). Inactivating mutations of $C D 58$ have been initially described in approximately one sixth of DLBCL with no preference for either cell of origin subtype (97). They are as frequent as mutations of $B 2 M$; in our study on 76 DLBCL in immunocompetent patients, the mutational frequency of $B 2 M$ was $16 \%$ (98). Interestingly, loss of CD58 cell surface expression is more commonly observed than assumed from its mutational frequency and many DLBCL show a concomitant loss of HLA class I and CD58. As loss of HLA class I alone might increase susceptibility to lysis by NK cells (99), the concomitant loss of CD58, which is a CD2 ligand, might act in a counterbalancing way. The reduced cytolysis of DLBCL cells lacking CD58 expression has been confirmed in cell culture experiments (97). CD58 mutations have also been described in a small percentage of peripheral T-cell lymphomas along with $B 2 M$ mutations (100). Mutations of $C D 58$ and $B 2 M$ are thought to be a main reason for non-responsiveness to immune checkpoint inhibition (101). Cao et al. showed that both mutations and copy number losses of CD58 and TP53 genes are independent unfavorable prognostic factors in DLBCL (102). This is the first study attributing such a high impact to CD58 mutations.

$B 2 M$ mutational rates vary in specific subtypes of DLBCL: in DLBCL of the testis and the central nervous system, i.e., DLBCL arising in immunoprivileged sites, $B 2 M$ mutations have been reported to be frequent (103), while in our study on posttransplant DLBCL, no B2M mutations were detected (104). From this finding, we concluded that $B 2 M$ mutations do not provide an additional advantage in the state of immunosuppression as there is, for obvious reasons, no genetic pressure for immune escape on the tumor cells.

\section{The CD70-CD27 Axis: Another Key to T-Cell Control}

CD27 belongs to the tumor necrosis factor family; it is involved in the activation of both innate and adaptive immunity. It is expressed in thymocytes and naïve T-cells as well as activated T-cells (105), memory B-cells (106), and NK cells in the bone marrow but not in circulating NK cells (107). CD27 has a unique ligand, CD70, which has become a focus of potential therapeutic interaction. A plethora of different tumor entities including many lymphomas (Figure 4) have been shown to express CD70 


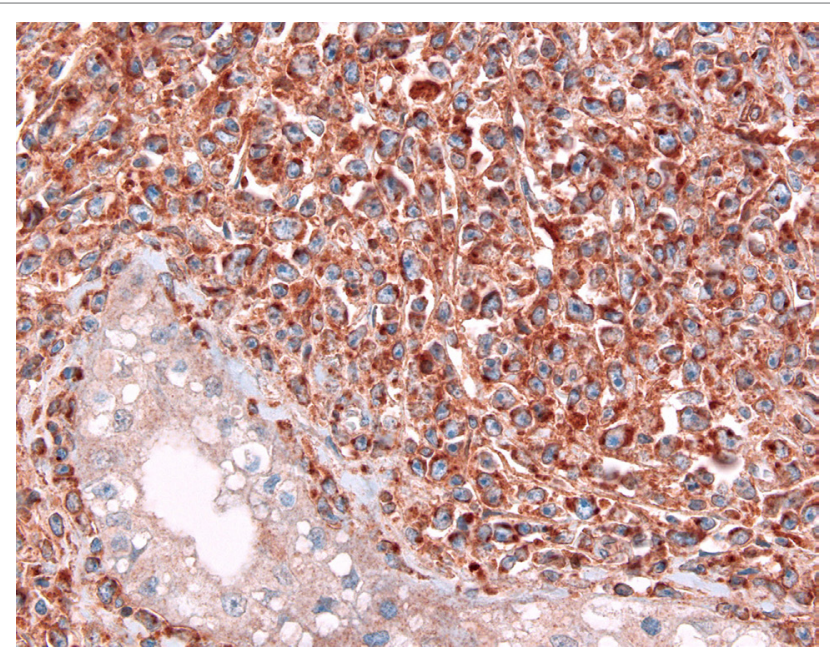

FIGURE 4 | Expression of CD70 in a testicular diffuse large B-cell lymphoma; note a negative seminiferous canaliculus.

$(108,109)$, whereas CD27 expression is primarily restricted to hematopoietic tumors (108). Tumors use the CD70-CD27 axis in order to manipulate T-cells in an immunosuppressive manner by increasing the proportion of inhibitory regulatory FoxP3 ${ }^{+} \mathrm{T}$-cells (110), induction of T-cell apoptosis (111), and skewing T-cells toward anergy and exhaustion (112).

First studies using monoclonal antibodies directed against CD70 have been tested with rather low response rates [complete remission in 1/19 lymphoma patients (113)]. Currently, several trials of combining anti-CD70 therapy and chemotherapy and radiotherapy are ongoing. The rationale behind this approach is that by activating the immunosurveillance of the microenvironment by CD70 blockade, the effect of conventional chemotherapy and radiotherapy is increased (114).

\section{EBV-The Classical Model of Oncogenicity and Immune Escape}

Epstein-Barr virus's role in lymphomagenesis was first discovered in Burkitt lymphoma (BL). While the MYC translocation is important for upholding the proliferative activity of $\mathrm{BL}$, the main effect of EBV is thought to be effectively preventing c-mycinduced apoptosis (115). EBV-infected non-neoplastic memory B-cells express only one EBV-specific protein (EBNA1) - known as "latency type 1"-in order to avoid recognition by the immune system, and these cells provide the life-long reservoir of EBV in humans. This latency type 1 is sustained in many B-cell lymphomas including BL, DLBCL and terminally differentiated B-cell lymphomas, while in cHL and many NK- and T-cell lymphomas, virus-infected tumor cells express to a certain extent LMP1 and LMP2A\&B (without EBNA2), known as latency type 2, and in lymphomas of immunosuppressed individuals EBNA2-3C are expressed along with LMPs, referred to as latency type 3 (116). Importantly, latency type 2 is an intriguing therapeutic target for PD1/PDL1-blocking agents as exemplified in $\mathrm{cHL}$ and NK/T-cell lymphomas $(29,61)$, while the latter latency type 3 would be recognizable by a functional immune system and is tolerated due to the concomitant immunosuppression in affected individuals as exemplified by recurrent tumor control in seldom instances, in which the respective immunosuppression can be restored $(117,118)$ (see also: expansion of decreased $\mathrm{T}$ helper 1 and $\mathrm{CD}^{+} \mathrm{T}$ cell subsets associates with regression of lymphoproliferative disorders developed during methotrexate treatment. Saito et al., published in the same journal issue). Even more, EBV relatedness in several of the above listed instances may even stand for distinct diseases, as it has been shown for DLBCL and PTLD (104) and recently also for plasmablastic lymphoma (119) that EBV-positive and EBV-negative tumors have both different pathogenesis as well as different prognosis. EBV exerts effects on the tumor cells related to proliferation and preventing apoptosis, and on the microenvironment, particularly on the host's immune system. In the setting of human immunodeficiency virus (HIV) infection, a marked increase of EBV-related lymphomas has been initially observed (120). With the introduction of highly active antiretroviral therapy (HAART), the incidence of HIV-related lymphomas has considerably changed: while there was a steep decline of EBV-associated lymphomas of the CNS and DLBCL, CHL incidence has risen, and the incidence of BL has remained stable (121). This shows that the risk to develop certain types of lymphoma is related to the function of the immune system. While several subtypes thrive in severe immune suppression (EBV-related DLBCL in general), $\mathrm{cHL}$ is dependent on an at least partially functioning immune system due to HRS cell interaction with the microenvironment, particularly their dependence on $\mathrm{CD}^{+} \mathrm{T}$-cell signaling (122), and thus their restoration by HAART "paradoxically" promotes cHL development. In BL, it is postulated that the expansion of the germinal center reaction and the pronounced activation of polyclonal B-cells seen in the early stages of HIV-induced by several viral proteins (123) - increases the amount of EBV-infected B-cells with MYC translocations (115). This reservoir of translocated and virusinfected B-cells, already "replenished" at the very beginning of HIV infection, increases the risk of BL outgrowths, which is independent of future control over HIV.

Apart from improving T-cell function and numbers, a key to treatment of EBV-related lymphoma is modulation of the ubiquitin-proteasome system. This vital cell component is used by EBV in several ways: it is inhibited by the virus to foster immune evasion (124); furthermore, it is used for modulation of cell cycle checkpoint proteins such as proto-oncogene serine/ threonine protein kinase 1 (PIM1) (125) or tumor suppressors such as p16 and retinoblastoma protein (pRb) (126); finally, it is involved in inhibition of apoptosis by fostering degradation of p53 and BCL6. The proof of concept of inhibiting the ubiquitin-proteasome system has been delivered in several EBV-associated malignancies (both carcinomas and lymphomas); however, larger clinical trials for testing this approach in the clinical setting are still required (127). In plasmablastic lymphoma, which is EBV-associated in the vast majority of cases (128), bortezomib treatment has already shown considerable improvement of treatment response and survival rates in small cohorts (129). 


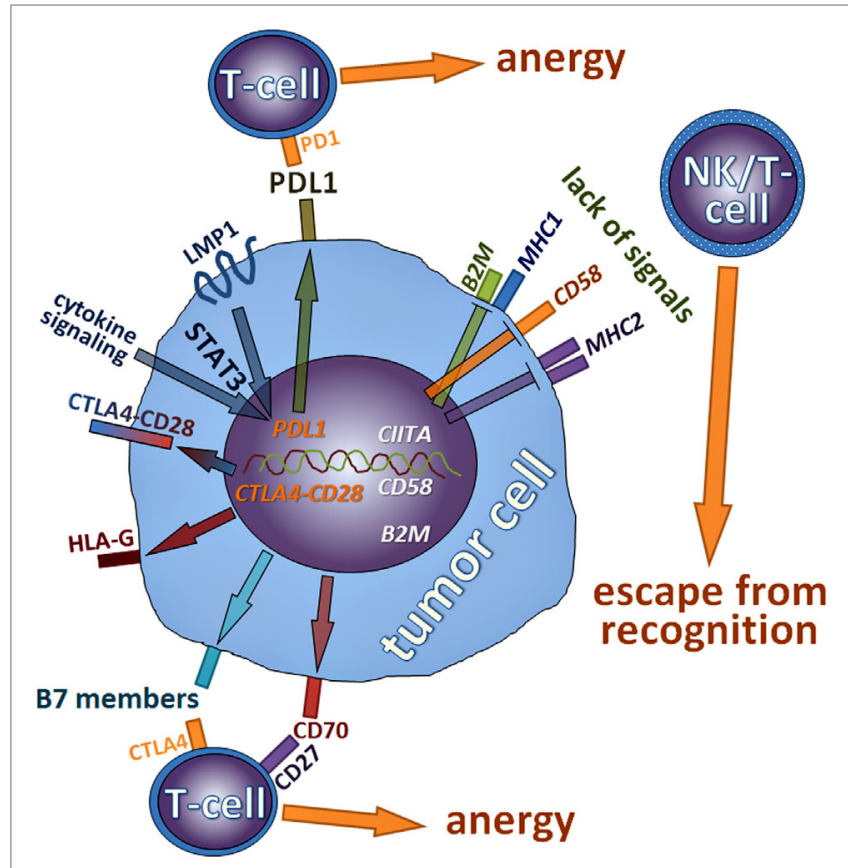

FIGURE 5 | Schematic summary of mechanisms discussed in this review Iymphoma cells employ to influence or circumvent the immune system; molecules that are rather repressed are in italics; genes inactivated by mutations are in white color, while those activated are in orange.

\section{Hematological Side Effects of Immunomodulative Therapies}

Adverse events (AE)/side effects of immune checkpoint inhibition drugs are reported to be rarer than those of classical chemotherapy agents (130). In contrast to the well understood genesis of pathologic changes in peripheral organs, which can mainly be explained by a graft-versus-host-like pathophysiology, the underlying mechanisms for hematological side effects of checkpoint inhibitors are not yet fully understood. Hematological $\mathrm{AE}$ in general seem to be more common in lymphoma patients than in patients treated for solid tumors (131). They manifest as isolated neutropenia, thrombocytopenia, or anemia, in some cases as pancytopenia, which may all have in common decreased auto-tolerance mechanisms under immunomodulation (132). Furthermore, development of hemophilia A in patients treated with anti-CTLA4 antibodies has been described $(133,134)$. In one study on DLBCL patients, a condition referred to as myelodysplastic syndrome (MDS) occurred in a single patient and was listed among the AE (131). However, in our point of view, it is difficult to attribute a MDS to immune checkpoint inhibition as several potential other causes should be considered (e.g., therapy-associated myeloid neoplasm after several previous

\section{REFERENCES}

1. Lipson EJ, Forde PM, Hammers HJ, Emens LA, Taube JM, Topalian SL. Antagonists of PD-1 and PD-L1 in cancer treatment. Semin Oncol (2015) 42(4):587-600.1. doi:10.1053/j.seminoncol.2015.05.013 chemotherapy courses!) and the mechanism how immune checkpoint inhibitors entice MDS-related mutations remains completely unclear. Though the pathophysiology of hematological $\mathrm{AE}$ seen in the context of immunomodulative therapies is not fully elucidated yet, it is highly likely that they develop in an autoimmune disease-like manner. In AE suspect instances, it is vital to rule out other potential causes of cytopenias such as lymphomatous bone marrow involvement, substrate deficiencies or toxicities of former (chemo-)therapies including evolving therapy-associated myeloid neoplasms, concomitant treatment with myelotoxic medications, e.g., certain NSAR, mycophenolate, or mTOR inhibitors (135). Interestingly, occurrence or worsening of graft-versus-host disease (GvHD) in previously transplanted individuals, whom immune checkpoint inhibition was given, has been reported as an $\mathrm{AE}$ in some studies, while others reported a reduced incidence (132). Importantly, in an experimental setting, PDL1 inhibition reduced GvHD without hampering the graft versus lymphoma effect in mice (136).

\section{CONCLUSION}

In this review, we have summarized mechanisms lymphoma cells employ to influence or circumvent the immune system (Figure 5). We have shown that many mutations and pathway alterations discovered in $\mathrm{CHL}-$ the pathognomonic example for a lymphoma interfering with the immune system-can also be found in other types of lymphomas and that these alterations, to which many lymphomas are oncogenically addicted, can be specifically targeted. Indeed, it has become evident that manipulating the immune system taints to be an advantageous management strategy for many tumors including lymphomas. Thorough research has elucidated several mechanisms how this is achieved, it has also become clear that both tumor cells and microenvironmental compounds should be considered and modulated in a proper manner. These findings have led to a plethora of new potential treatment options, which have already proven to be beneficiary for patients.

However, it has also become evident that there is no uniform treatment response, highlighting the need for individualized analysis of patients' tumors and the corresponding individual immunological/immunogenetic background in order to decipher on the one hand the specific pathways used by the tumor to hamper the hosts' immune system and the potential responsiveness of the latter. It has also become evident that immunotherapy can and probably should be synthetically combined with the other pillars of cancer therapy - surgery, chemotherapy, and radiotherapy - as this can markedly improve the impact of each therapy approach.

\section{AUTHOR CONTRIBUTIONS}

Both AT and TM conceived and wrote the manuscript.

2. Hahn T, McCarthy PL Jr, Hassebroek A, Bredeson C, Gajewski JL, Hale GA, et al. Significant improvement in survival after allogeneic hematopoietic cell transplantation during a period of significantly increased use, older recipient age, and use of unrelated donors. J Clin Oncol (2013) 31(19):2437-49. doi:10.1200/JCO.2012.46.6193 
3. Pardoll D. Cancer and the immune system: basic concepts and targets for intervention. Semin Oncol (2015) 42(4):523-38. doi:10.1053/j.seminoncol. 2015.05.003

4. Rygaard J, Povlsen CO. The nude mouse vs. the hypothesis of immunological surveillance. Transplant Rev (1976) 28:43-61.

5. Shankaran V, Ikeda H, Bruce AT, White JM, Swanson PE, Old LJ, et al. IFNgamma and lymphocytes prevent primary tumour development and shape tumour immunogenicity. Nature (2001) 410(6832):1107-11. doi:10.1038/35074122

6. Dunn GP, Koebel CM, Schreiber RD. Interferons, immunity and cancer immunoediting. Nat Rev Immunol (2006) 6(11):836-48. doi:10.1038/nri1961

7. Hoenicke L, Zender L. Immune surveillance of senescent cells - biological significance in cancer- and non-cancer pathologies. Carcinogenesis (2012) 33(6):1123-6. doi:10.1093/carcin/bgs124

8. Muenst S, Laubli H, Soysal SD, Zippelius A, Tzankov A, Hoeller S. The immune system and cancer evasion strategies: therapeutic concepts. J Intern Med (2016) 279(6):541-62. doi:10.1111/joim.12470

9. Selvan SR, Dowling JP, Kelly WK, Lin J. Indoleamine 2,3-dioxygenase (IDO): biology and target in cancer immunotherapies. Curr Cancer Drug Targets (2016) 16(9):755-64. doi:10.2174/1568009615666151030102250

10. Ward-Hartstonge KA, Kemp RA. Regulatory T-cell heterogeneity and the cancer immune response. Clin Transl Immunology (2017) 6(9):e154.1. doi:10.1038/cti.2017.43

11. Chaudhary B, Elkord E. Regulatory T cells in the tumor microenvironment and cancer progression: role and therapeutic targeting. Vaccines (Basel) (2016) 4(3):28. doi:10.3390/vaccines4030028

12. Prendergast GC, Malachowski WP, DuHadaway JB, Muller AJ. Discovery of IDO1 inhibitors: from bench to bedside. Cancer Res (2017) 77(24):6795-811. doi:10.1158/0008-5472.CAN-17-2285

13. Prendergast GC, Smith C, Thomas S, Mandik-Nayak L, Laury-Kleintop L, Metz R, et al. Indoleamine 2,3-dioxygenase pathways of pathogenic inflammation and immune escape in cancer. Cancer Immunol Immunother (2014) 63(7):721-35. doi:10.1007/s00262-014-1549-4

14. Lippitz BE. Cytokine patterns in patients with cancer: a systematic review. Lancet Oncol (2013) 14(6):e218-28. doi:10.1016/S1470-2045(12)70582-X

15. Rybinski B, Yun K. Addressing intra-tumoral heterogeneity and therapy resistance. Oncotarget (2016) 7(44):72322-42. doi:10.18632/oncotarget.11875

16. Sathyanarayanan V, Neelapu SS. Cancer immunotherapy: strategies for personalization and combinatorial approaches. Mol Oncol (2015) 9(10):2043-53. doi:10.1016/j.molonc.2015.10.009

17. Diehl V. Hodgkin's disease - from pathology specimen to cure. N Engl J Med (2007) 357(19):1968-71. doi:10.1056/NEJMe078173

18. Carey CD, Gusenleitner D, Lipschitz M, Roemer MGM, Stack EC, Gjini E, et al. Topological analysis reveals a PD-L1-associated microenvironmental niche for Reed-Sternberg cells in Hodgkin lymphoma. Blood (2017) 130(22):2420-30. doi:10.1182/blood-2017-03-770719

19. Gordon SR, Maute RL, Dulken BW, Hutter G, George BM, McCracken MN, et al. PD-1 expression by tumour-associated macrophages inhibits phagocytosis and tumour immunity. Nature (2017) 545(7655):495-9. doi:10.1038/ nature22396

20. Kuppers R, Rajewsky K, Zhao M, Simons G, Laumann R, Fischer R, et al. Hodgkin disease: Hodgkin and Reed-Sternberg cells picked from histological sections show clonal immunoglobulin gene rearrangements and appear to be derived from B cells at various stages of development. Proc Natl Acad Sci U S A (1994) 91(23):10962-6. doi:10.1073/pnas.91.23.10962

21. Marafioti T, Hummel M, Foss HD, Laumen H, Korbjuhn P, Anagnostopoulos I, et al. Hodgkin and Reed-Sternberg cells represent an expansion of a single clone originating from a germinal center B-cell with functional immunoglobulin gene rearrangements but defective immunoglobulin transcription. Blood (2000) 95(4):1443-50.

22. Schwering I, Brauninger A, Klein U, Jungnickel B, Tinguely M, Diehl V, et al. Loss of the B-lineage-specific gene expression program in Hodgkin and Reed-Sternberg cells of Hodgkin lymphoma. Blood (2003) 101(4):1505-12. doi:10.1182/blood-2002-03-0839

23. Mathas S, Hartmann S, Kuppers R. Hodgkin lymphoma: pathology and biology. Semin Hematol (2016) 53(3):139-47. doi:10.1053/j. seminhematol.2016.05.007

24. Reichel J, Chadburn A, Rubinstein PG, Giulino-Roth L, Tam W, Liu Y, et al. Flow sorting and exome sequencing reveal the oncogenome of primary Hodgkin and Reed-Sternberg cells. Blood (2015) 125(7):1061-72. doi:10.1182/blood-2014-11-610436

25. Roemer MG, Advani RH, Ligon AH, Natkunam Y, Redd RA, Homer H, et al. PD-L1 and PD-L2 genetic alterations define classical Hodgkin lymphoma and predict outcome. J Clin Oncol (2016) 34(23):2690-7. doi:10.1200/ JCO.2016.66.4482

26. Green MR, Monti S, Rodig SJ, Juszczynski P, Currie T, O’Donnell E, et al. Integrative analysis reveals selective 9p24.1 amplification, increased PD-1 ligand expression, and further induction via JAK2 in nodular sclerosing Hodgkin lymphoma and primary mediastinal large B-cell lymphoma. Blood (2010) 116(17):3268-77. doi:10.1182/blood-2010-05-282780

27. Menter T, Bodmer-Haecki A, Dirnhofer S, Tzankov A. Evaluation of the diagnostic and prognostic value of PDL1 expression in Hodgkin and B-cell lymphomas. Hum Pathol (2016) 54:17-24.1. doi:10.1016/j.humpath.2016.03.005

28. Chen BJ, Chapuy B, Ouyang J, Sun HH, Roemer MG, Xu ML, et al. PD-L1 expression is characteristic of a subset of aggressive B-cell lymphomas and virus-associated malignancies. Clin Cancer Res (2013) 19(13):3462-73. doi:10.1158/1078-0432.CCR-13-0855

29. Ansell SM, Lesokhin AM, Borrello I, Halwani A, Scott EC, Gutierrez M, et al. PD-1 blockade with nivolumab in relapsed or refractory Hodgkin's lymphoma. N Engl J Med (2015) 372(4):311-9. doi:10.1056/NEJMoa1411087

30. Rui L, Emre NC, Kruhlak MJ, Chung HJ, Steidl C, Slack G, et al. Cooperative epigenetic modulation by cancer amplicon genes. Cancer Cell (2010) 18(6):590-605.1. doi:10.1016/j.ccr.2010.11.013

31. Younes A, Santoro A, Shipp M, Zinzani PL, Timmerman JM, Ansell S, et al. Nivolumab for classical Hodgkin's lymphoma after failure of both autologous stem-cell transplantation and brentuximab vedotin: a multicentre, multicohort, single-arm phase 2 trial. Lancet Oncol (2016) 17(9):1283-94. doi:10.1016/S1470-2045(16)30167-X

32. Steidl C, Shah SP, Woolcock BW, Rui L, Kawahara M, Farinha P, et al. MHC class II transactivator CIITA is a recurrent gene fusion partner in lymphoid cancers. Nature (2011) 471(7338):377-81. doi:10.1038/nature09754

33. Diepstra A, van Imhoff GW, Karim-Kos HE, van den Berg A, te Meerman GJ, Niens M, et al. HLA class II expression by Hodgkin Reed-Sternberg cells is an independent prognostic factor in classical Hodgkin's lymphoma. J Clin Oncol (2007) 25(21):3101-8. doi:10.1200/JCO.2006.10.0917

34. Roemer MG, Advani RH, Redd RA, Pinkus GS, Natkunam Y, Ligon AH, et al. Classical Hodgkin lymphoma with reduced beta2M/MHC class I expression is associated with inferior outcome independent of 9p24.1 status. Cancer Immunol Res (2016) 4(11):910-6. doi:10.1158/2326-6066.CIR-16-0201

35. Ellis PA, Hart DN, Colls BM, Nimmo JC, MacDonald JE, Angus HB. Hodgkin's cells express a novel pattern of adhesion molecules. Clin Exp Immunol (1992) 90(1):117-23. doi:10.1111/j.1365-2249.1992.tb05842.x

36. Schneider M, Schneider S, Zuhlke-Jenisch R, Klapper W, Sundstrom C, Hartmann S, et al. Alterations of the CD58 gene in classical Hodgkin lymphoma. Genes Chromosomes Cancer (2015) 54(10):638-45. doi:10.1002/ gcc. 22276

37. Abdul Razak FR, Diepstra A, Visser L, van den Berg A. CD58 mutations are common in Hodgkin lymphoma cell lines and loss of CD58 expression in tumor cells occurs in Hodgkin lymphoma patients who relapse. Genes Immun (2016) 17(6):363-6. doi:10.1038/gene.2016.30

38. Caocci G, Greco M, Fanni D, Senes G, Littera R, Lai S, et al. HLA-G expression and role in advanced-stage classical Hodgkin lymphoma. Eur J Histochem (2016) 60(2):2606.1. doi:10.4081/ejh.2016.2606

39. Kapatai G, Murray P. Contribution of the Epstein Barr virus to the molecular pathogenesis of Hodgkin lymphoma. J Clin Pathol (2007) 60(12):1342-9. doi:10.1136/jcp.2007.050146

40. Mancao C, Altmann M, Jungnickel B, Hammerschmidt W. Rescue of "crippled"germinal center B cells from apoptosis by Epstein-Barr virus. Blood (2005) 106(13):4339-44. doi:10.1182/blood-2005-06-2341

41. Renne C, Hinsch N, Willenbrock K, Fuchs M, Klapper W, Engert A, et al. The aberrant coexpression of several receptor tyrosine kinases is largely restricted to EBV-negative cases of classical Hodgkin's lymphoma. Int J Cancer (2007) 120(11):2504-9. doi:10.1002/ijc.22511

42. Green MR, Rodig S, Juszczynski P, Ouyang J, Sinha P, O’Donnell E, et al. Constitutive AP-1 activity and EBV infection induce PD-L1 in Hodgkin lymphomas and posttransplant lymphoproliferative disorders: implications for targeted therapy. Clin Cancer Res (2012) 18(6):1611-8. doi:10.1158/10780432.CCR-11-1942 
43. Kuppers R. New insights in the biology of Hodgkin lymphoma. Hematology Am Soc Hematol Educ Program (2012) 2012:328-34. doi:10.1182/ asheducation-2012.1.328

44. Skinnider BF, Mak TW. The role of cytokines in classical Hodgkin lymphoma. Blood (2002) 99(12):4283-97. doi:10.1182/blood-2002-01-0099

45. Liu WR, Shipp MA. Signaling pathways and immune evasion mechanisms in classical Hodgkin lymphoma. Blood (2017) 130(21):2265-70. doi:10.1182/ blood-2017-06-781989

46. Ishida Y, Agata Y, Shibahara K, Honjo T. Induced expression of PD-1, a novel member of the immunoglobulin gene superfamily, upon programmed cell death. EMBO J (1992) 11(11):3887-95.

47. Dong H, Zhu G, Tamada K, Chen L. B7-H1, a third member of the B7 family, co-stimulates T-cell proliferation and interleukin-10 secretion. Nat Med (1999) 5(12):1365-9. doi:10.1038/70932

48. Messal N, Serriari NE, Pastor S, Nunes JA, Olive D. PD-L2 is expressed on activated human T cells and regulates their function. Mol Immunol (2011) 48(15-16):2214-9. doi:10.1016/j.molimm.2011.06.436

49. Zhang X, Schwartz JC, Guo X, Bhatia S, Cao E, Lorenz M, et al. Structural and functional analysis of the costimulatory receptor programmed death-1. Immunity (2004) 20(3):337-47. doi:10.1016/S1074-7613(04)00051-2

50. Francisco LM, Salinas VH, Brown KE, Vanguri VK, Freeman GJ, Kuchroo VK, et al. PD-L1 regulates the development, maintenance, and function of induced regulatory T cells. J Exp Med (2009) 206(13):3015-29. doi:10.1084/ jem. 20090847

51. Steidl C, Lee T, Shah SP, Farinha P, Han G, Nayar T, et al. Tumor-associated macrophages and survival in classic Hodgkin's lymphoma. $N$ Engl J Med (2010) 362(10):875-85. doi:10.1056/NEJMoa0905680

52. Guo B, Cen H, Tan X, Ke Q. Meta-analysis of the prognostic and clinical value of tumor-associated macrophages in adult classical Hodgkin lymphoma. BMC Med (2016) 14(1):159.1. doi:10.1186/s12916-016-0711-6

53. Tivol EA, Borriello F, Schweitzer AN, Lynch WP, Bluestone JA, Sharpe AH. Loss of CTLA- 4 leads to massive lymphoproliferation and fatal multiorgan tissue destruction, revealing a critical negative regulatory role of CTLA-4. Immunity (1995) 3(5):541-7. doi:10.1016/1074-7613(95)90125-6

54. Nishimura H, Okazaki T, Tanaka Y, Nakatani K, Hara M, Matsumori A, et al. Autoimmune dilated cardiomyopathy in $\mathrm{PD}-1$ receptor-deficient mice. Science (2001) 291(5502):319-22. doi:10.1126/science.291.5502.319

55. Muenst S, Soysal SD, Tzankov A, Hoeller S. The PD-1/PD-L1 pathway: biological background and clinical relevance of an emerging treatment target in immunotherapy. Expert Opin Ther Targets (2015) 19(2):201-11. doi:10.1517/ 14728222.2014.980235

56. Sheppard KA, Fitz LJ, Lee JM, Benander C, George JA, Wooters J, et al. PD-1 inhibits T-cell receptor induced phosphorylation of the ZAP70/CD3zeta signalosome and downstream signaling to PKCtheta. FEBS Lett (2004) 574(1-3):37-41.1. doi:10.1016/j.febslet.2004.07.083

57. Karwacz K, Bricogne C, MacDonald D, Arce F, Bennett CL, Collins M, et al. PD-L1 co-stimulation contributes to ligand-induced T cell receptor down-modulation on CD8+ T cells. EMBO Mol Med (2011) 3(10):581-92. doi:10.1002/emmm.201100165

58. Zuazo M, Gato-Canas M, Llorente N, Ibanez-Vea M, Arasanz H, Kochan G, et al. Molecular mechanisms of programmed cell death-1 dependent T cell suppression: relevance for immunotherapy. Ann Transl Med (2017) 5(19):385.1. doi:10.21037/atm.2017.06.11

59. Kiyasu J, Miyoshi H, Hirata A, Arakawa F, Ichikawa A, Niino D, et al. Expression of programmed cell death ligand 1 is associated with poor overall survival in patients with diffuse large B-cell lymphoma. Blood (2015) 126(19):2193-201. doi:10.1182/blood-2015-02-629600

60. Brusa D, Serra S, Coscia M, Rossi D, D'Arena G, Laurenti L, et al. The PD-1/PD-L1 axis contributes to T-cell dysfunction in chronic lymphocytic leukemia. Haematologica (2013) 98(6):953-63. doi:10.3324/haematol.2012. 077537

61. Chan TSY, Li J, Loong F, Khong PL, Tse E, Kwong YL. PD1 blockade with low-dose nivolumab in NK/T cell lymphoma failing L-asparaginase: efficacy and safety. Ann Hematol (2017) 97(1):193-6. doi:10.1007/s00277-017$3127-2$

62. Twa DD, Chan FC, Ben-Neriah S, Woolcock BW, Mottok A, Tan KL, et al. Genomic rearrangements involving programmed death ligands are recurrent in primary mediastinal large B-cell lymphoma. Blood (2014) 123(13): 2062-5. doi:10.1182/blood-2013-10-535443
63. Georgiou K, Chen L, Berglund M, Ren W, de Miranda NF, Lisboa S, et al. Genetic basis of PD-L1 overexpression in diffuse large B-cell lymphomas. Blood (2016) 127(24):3026-34. doi:10.1182/blood-2015-12-686550

64. Chapuy B, Roemer MG, Stewart C, Tan Y, Abo RP, Zhang L, et al. Targetable genetic features of primary testicular and primary central nervous system lymphomas. Blood (2016) 127(7):869-81. doi:10.1182/blood-2015-10-673236

65. Marzec M, Zhang Q, Goradia A, Raghunath PN, Liu X, Paessler M, et al. Oncogenic kinase NPM/ALK induces through STAT3 expression of immunosuppressive protein CD274 (PD-L1, B7-H1). Proc Natl Acad Sci U S A (2008) 105(52):20852-7. doi:10.1073/pnas.0810958105

66. Chikuma S, Kanamori M, Mise-Omata S, Yoshimura A. Suppressors of cytokine signaling: potential immune checkpoint molecules for cancer immunotherapy. Cancer Sci (2017) 108(4):574-80. doi:10.1111/cas.13194

67. Kataoka K, Shiraishi Y, Takeda Y, Sakata S, Matsumoto M, Nagano S, et al. Aberrant PD-L1 expression through 3'-UTR disruption in multiple cancers. Nature (2016) 534(7607):402-6. doi:10.1038/nature18294

68. Xing W, Dresser K, Zhang R, Evens AM, Yu H, Woda BA, et al. PD-L1 expression in EBV-negative diffuse large B-cell lymphoma: clinicopathologic features and prognostic implications. Oncotarget (2016) 7(37):59976-86. doi:10.18632/oncotarget.11045

69. Nayak L, Iwamoto FM, LaCasce A, Mukundan S, Roemer MGM, Chapuy B, et al. PD-1 blockade with nivolumab in relapsed/refractory primary central nervous system and testicular lymphoma. Blood (2017) 129(23):3071-3. doi:10.1182/blood-2017-01-764209

70. Bledsoe JR, Redd RA, Hasserjian RP, Soumerai JD, Nishino HT, Boyer DF, et al. The immunophenotypic spectrum of primary mediastinal large B-cell lymphoma reveals prognostic biomarkers associated with outcome. Am J Hematol (2016) 91(10):E436-41. doi:10.1002/ajh.24485

71. Vranic S, Ghosh N, Kimbrough J, Bilalovic N, Bender R, Arguello D, et al. PD-L1 status in refractory lymphomas. PLoS One (2016) 11(11):e0166266.1. doi:10.1371/journal.pone.0166266

72. Merryman RW, Armand P, Wright KT, Rodig SJ. Checkpoint blockade in Hodgkin and non-Hodgkin lymphoma. Blood Adv (2017) 1(26):2643-5. doi:10.1182/bloodadvances.2017012534

73. Brunet JF, Denizot F, Luciani MF, Roux-Dosseto M, Suzan M, Mattei MG, et al. A new member of the immunoglobulin superfamily - CTLA-4. Nature (1987) 328(6127):267-70. doi:10.1038/328267a0

74. Takahashi T, Tagami T, Yamazaki S, Uede T, Shimizu J, Sakaguchi N, et al. Immunologic self-tolerance maintained by $\mathrm{CD} 25(+) \mathrm{CD} 4(+)$ regulatory $\mathrm{T}$ cells constitutively expressing cytotoxic $\mathrm{T}$ lymphocyte-associated antigen 4. J Exp Med (2000) 192(2):303-10. doi:10.1084/jem.192.2.303

75. Carreno BM, Bennett F, Chau TA, Ling V, Luxenberg D, Jussif J, et al. CTLA-4 (CD152) can inhibit $\mathrm{T}$ cell activation by two different mechanisms depending on its level of cell surface expression. J Immunol (2000) 165(3):1352-6. doi:10.4049/jimmunol.165.3.1352

76. Stamper CC, Zhang Y, Tobin JF, Erbe DV, Ikemizu S, Davis SJ, et al. Crystal structure of the B7-1/CTLA-4 complex that inhibits human immune responses. Nature (2001) 410(6828):608-11. doi:10.1038/35069118

77. Fraser JH, Rincon M, McCoy KD, Le Gros G. CTLA4 ligation attenuates AP-1, NFAT and NF-kappaB activity in activated T cells. Eur J Immunol (1999) 29(3): 838-44. doi:10.1002/(SICI)1521-4141(199903)29:03<838::AID-IMMU838>3.0. $\mathrm{CO} ; 2-\mathrm{P}$

78. Brunner MC, Chambers CA, Chan FK, Hanke J, Winoto A, Allison JP. CTLA4-mediated inhibition of early events of T cell proliferation. J Immunol (1999) 162(10):5813-20.

79. Calvo CR, Amsen D, Kruisbeek AM. Cytotoxic T lymphocyte antigen 4 (CTLA-4) interferes with extracellular signal-regulated kinase (ERK) and Jun NH2-terminal kinase (JNK) activation, but does not affect phosphorylation of T cell receptor zeta and ZAP70. J Exp Med (1997) 186(10):1645-53. doi:10.1084/jem.186.10.1645

80. Chen L, Flies DB. Molecular mechanisms of T cell co-stimulation and co-inhibition. Nat Rev Immunol (2013) 13(4):227-42. doi:10.1038/nri3405

81. Yoo HY, Kim P, Kim WS, LeeSH, Kim S, Kang SY, et al. Frequent CTLA4-CD28 gene fusion in diverse types of T-cell lymphoma. Haematologica (2016) 101(6):757-63. doi:10.3324/haematol.2015.139253

82. Shin JH, Park HB, Oh YM, Lim DP, Lee JE, Seo HH, et al. Positive conversion of negative signaling of CTLA4 potentiates antitumor efficacy of adoptive T-cell therapy in murine tumor models. Blood (2012) 119(24):5678-87. doi:10.1182/blood-2011-09-380519 
83. Herrmann A, Lahtz C, Nagao T, Song JY, Chan WC, Lee H, et al. CTLA4 promotes Tyk2-STAT3 dependent B cell oncogenecity. Cancer Res (2017) 77(18):5118-28. doi:10.1158/0008-5472.CAN-16-0342

84. Huang X, Meng B, Iqbal J, Ding BB, Perry AM, Cao W, et al. Activation of the STAT3 signaling pathway is associated with poor survival in diffuse large B-cell lymphoma treated with R-CHOP. J Clin Oncol (2013) 31(36):4520-8. doi:10.1200/JCO.2012.45.6004

85. Bashey A, Medina B, Corringham S, Pasek M, Carrier E, Vrooman L, et al. CTLA4 blockade with ipilimumab to treat relapse of malignancy after allogeneic hematopoietic cell transplantation. Blood (2009) 113(7):1581-8. doi:10.1182/blood-2008-07-168468

86. Diefenbach C, Hong F, Cohen J, Robertson M, Ambinder R, Fenske T, et al. Preliminary safety and efficacy of the combination of brentuximab vedotin and ipilimumab in relapsed/refractory Hodgkin lymphoma: a trial of the ECOG-ACRIN Cancer Research Group (E4412). Blood (2015) 126:abstr585.

87. Carosella ED, Moreau P, Lemaoult J, Rouas-Freiss N. HLA-G: from biology to clinical benefits. Trends Immunol (2008) 29(3):125-32. doi:10.1016/j. it.2007.11.005

88. Morandi F, Rizzo R, Fainardi E, Rouas-Freiss N, Pistoia V. Recent advances in our understanding of HLA-G biology: lessons from a wide spectrum of human diseases. J Immunol Res (2016) 2016:4326495.1. doi:10.1155/2016/ 4326495

89. Morandi F, Rouas-Freiss N, Pistoia V. The emerging role of soluble HLA-G in the control of chemotaxis. Cytokine Growth Factor Rev (2014) 25(3):327-35. doi:10.1016/j.cytogfr.2014.04.004

90. Baudhuin J, Migraine J, Faivre V, Loumagne L, Lukaszewicz AC, Payen D, et al. Exocytosis acts as a modulator of the ILT4-mediated inhibition of neutrophil functions. Proc Natl Acad Sci U S A (2013) 110(44):17957-62. doi: $10.1073 /$ pnas. 1221535110

91. Fons P, Chabot S, Cartwright JE, Lenfant F, L'Faqihi F, Giustiniani J, et al. Soluble HLA-G1 inhibits angiogenesis through an apoptotic pathway and by direct binding to CD160 receptor expressed by endothelial cells. Blood (2006) 108(8):2608-15. doi:10.1182/blood-2005-12-019919

92. Yan WH. HLA-G expression in hematologic malignancies. Expert Rev Hematol (2010) 3(1):67-80.1. doi:10.1586/ehm.09.72

93. Bielska M, Bojo M, Klimkiewicz-Wojciechowska G, Jesionek-Kupnicka D, Borowiec M, Kalinka-Warzocha E, et al. Human leukocyte antigen-G polymorphisms influence the clinical outcome in diffuse large B-cell lymphoma. Genes Chromosomes Cancer (2015) 54(3):185-93. doi:10.1002/gcc.22235

94. Rizzo R, Audrito V, Vacca P, Rossi D, Brusa D, Stignani M, et al. HLA-G is a component of the chronic lymphocytic leukemia escape repertoire to generate immune suppression: impact of the HLA-G 14 base pair (rs66554220) polymorphism. Haematologica (2014) 99(5):888-96. doi:10.3324/haematol. 2013.095281

95. Peaper DR, Cresswell P. Regulation of MHC class I assembly and peptide binding. Annu Rev Cell Dev Biol (2008) 24:343-68. doi:10.1146/annurev. cellbio.24.110707.175347

96. Wang D, Quan Y, Yan Q, Morales JE, Wetsel RA. Targeted disruption of the beta2-microglobulin gene minimizes the immunogenicity of human embryonic stem cells. Stem Cells Transl Med (2015) 4(10):1234-45. doi:10.5966/ sctm.2015-0049

97. Challa-Malladi M, Lieu YK, Califano O, Holmes AB, Bhagat G, Murty VV, et al. Combined genetic inactivation of beta2-microglobulin and CD58 reveals frequent escape from immune recognition in diffuse large B cell lymphoma. Cancer Cell (2011) 20(6):728-40. doi:10.1016/j.ccr.2011.11.006

98. Juskevicius D, Jucker D, Klingbiel D, Mamot C, Dirnhofer S, Tzankov A. Mutations of CREBBP and SOCS1 are independent prognostic factors in diffuse large B cell lymphoma: mutational analysis of the SAKK 38/07 prospective clinical trial cohort. J Hematol Oncol (2017) 10(1):70.1. doi:10.1186/ s13045-017-0438-7

99. Karre K, Ljunggren HG, Piontek G, Kiessling R. Selective rejection of H-2deficient lymphoma variants suggests alternative immune defence strategy. Nature (1986) 319(6055):675-8. doi:10.1038/319675a0

100. Palomero T, Couronne L, Khiabanian H, Kim MY, Ambesi-Impiombato A, Perez-Garcia A, et al. Recurrent mutations in epigenetic regulators, RHOA and FYN kinase in peripheral T cell lymphomas. Nat Genet (2014) 46(2): 166-70. doi:10.1038/ng.2873

101. Zaretsky JM, Garcia-Diaz A, Shin DS, Escuin-Ordinas H, Hugo W, $\mathrm{Hu}-\mathrm{Lieskovan} \mathrm{S}$, et al. Mutations associated with acquired resistance to PD-1 blockade in melanoma. N Engl J Med (2016) 375(9):819-29. doi:10.1056/ NEJMoa1604958

102. Cao Y, Zhu T, Zhang P, Xiao M, Yi S, Yang Y, et al. Mutations or copy number losses of CD58 and TP53 genes in diffuse large B cell lymphoma are independent unfavorable prognostic factors. Oncotarget (2016) 7(50):83294-307. doi:10.18632/oncotarget.13065

103. Jordanova ES, Riemersma SA, Philippo K, Schuuring E, Kluin PM. Beta2microglobulin aberrations in diffuse large B-cell lymphoma of the testis and the central nervous system. Int J Cancer (2003) 103(3):393-8. doi:10.1002/ ijc. 10824

104. Menter T, Juskevicius D, Alikian M, Steiger J, Dirnhofer S, Tzankov A, et al. Mutational landscape of B-cell post-transplant lymphoproliferative disorders. Br J Haematol (2017) 178(1):48-56.1. doi:10.1111/bjh.14633

105. Hintzen RQ, Lens SM, Beckmann MP, Goodwin RG, Lynch D, van Lier RA. Characterization of the human CD27 ligand, a novel member of the TNF gene family. J Immunol (1994) 152(4):1762-73.

106. Jacquot S, Kobata T, Iwata S, Morimoto C, Schlossman SF. CD154/CD40 and CD70/CD27 interactions have different and sequential functions in T cell-dependent B cell responses: enhancement of plasma cell differentiation by CD27 signaling. J Immunol (1997) 159(6):2652-7.

107. Vossen MT, Matmati M, Hertoghs KM, Baars PA, Gent MR, Leclercq G, et al. CD27 defines phenotypically and functionally different human NK cell subsets. J Immunol (2008) 180(6):3739-45. doi:10.4049/jimmunol. 180.6.3739

108. Lens SM, Drillenburg P, den Drijver BF, van Schijndel G, Pals ST, van Lier RA, et al. Aberrant expression and reverse signalling of CD70 on malignant B cells. Br J Haematol (1999) 106(2):491-503. doi:10.1046/j.1365-2141.1999. 01573.x

109. Adam PJ, Terrett JA, Steers G, Stockwin L, Loader JA, Fletcher GC, et al. CD70 (TNFSF7) is expressed at high prevalence in renal cell carcinomas and is rapidly internalised on antibody binding. Br J Cancer (2006) 95(3):298-306.1 doi:10.1038/sj.bjc.6603222

110. Yang ZZ, Novak AJ, Stenson MJ, Witzig TE, Ansell SM. Intratumoral CD4+CD25+ regulatory T-cell-mediated suppression of infiltrating CD4+ T cells in B-cell non-Hodgkin lymphoma. Blood (2006) 107(9):3639-46. doi:10.1182/blood-2005-08-3376

111. Chahlavi A, Rayman P, Richmond AL, Biswas K, Zhang R, Vogelbaum M, et al. Glioblastomas induce T-lymphocyte death by two distinct pathways involving gangliosides and CD70. Cancer Res (2005) 65(12):5428-38. doi:10.1158/0008-5472.CAN-04-4395

112. Yang ZZ, Grote DM, Xiu B, Ziesmer SC, Price-Troska TL, Hodge LS, et al. TGF-beta upregulates CD70 expression and induces exhaustion of effector memory T cells in B-cell non-Hodgkin's lymphoma. Leukemia (2014) 28(9):1872-84. doi:10.1038/leu.2014.84

113. Ryan MC, Kostner H, Gordon KA, Duniho S, Sutherland MK, Yu C, et al. Targeting pancreatic and ovarian carcinomas using the auristatin-based anti-CD70 antibody-drug conjugate SGN-75. Br J Cancer (2010) 103(5): 676-84. doi:10.1038/sj.bjc.6605816

114. Ghiringhelli F, Apetoh L. The interplay between the immune system and chemotherapy: emerging methods for optimizing therapy. Expert Rev Clin Immunol (2014) 10(1):19-30.1. doi:10.1586/1744666X.2014.865520

115. Allday MJ. How does Epstein-Barr virus (EBV) complement the activation of Myc in the pathogenesis of Burkitt's lymphoma? Semin Cancer Biol (2009) 19(6):366-76. doi:10.1016/j.semcancer.2009.07.007

116. Grywalska E, Rolinski J. Epstein-Barr virus-associated lymphomas. Semin Oncol (2015) 42(2):291-303.1. doi:10.1053/j.seminoncol.2014.12.030

117. Barker JN, Doubrovina E, Sauter C, Jaroscak JJ, Perales MA, Doubrovin M, et al. Successful treatment of EBV-associated posttransplantation lymphoma after cord blood transplantation using third-party EBV-specific cytotoxic T lymphocytes. Blood (2010) 116(23):5045-9. doi:10.1182/blood-201004-281873

118. Manz MG, Berger C, Horny HP, Beck R, Brugger W, Viebahn R, et al. Sustained remission of an extensive monoclonal, Epstein-Barr virus-associated diffuse large B cell lymphoma in a kidney-pancreas transplant recipient. Transplantation (2002) 73(6):995-7. doi:10.1097/00007890-200203270-00030

119. Laurent C, Fabiani B, Do C, Tchernonog E, Cartron G, Gravelle P, et al. Immune-checkpoint expression in Epstein-Barr virus positive and negative plasmablastic lymphoma: a clinical and pathological study in 82 patients. Haematologica (2016) 101(8):976-84. doi:10.3324/haematol.2016.141978 
120. Cesarman E. Gammaherpesviruses and lymphoproliferative disorders. Annu Rev Pathol (2014) 9:349-72. doi:10.1146/annurev-pathol-012513-104656

121. Vockerodt M, Yap LF, Shannon-Lowe C, Curley H, Wei W, Vrzalikova K, et al. The Epstein-Barr virus and the pathogenesis of lymphoma. J Pathol (2015) 235(2):312-22. doi:10.1002/path.4459

122. Biggar RJ, Jaffe ES, Goedert JJ, Chaturvedi A, Pfeiffer R, Engels EA. Hodgkin lymphoma and immunodeficiency in persons with HIV/AIDS. Blood (2006) 108(12):3786-91. doi:10.1182/blood-2006-05-024109

123. Pinzone MR, Berretta M, Cacopardo B, Nunnari G. Epstein-Barr virusand Kaposi sarcoma-associated herpesvirus-related malignancies in the setting of human immunodeficiency virus infection. Semin Oncol (2015) 42(2):258-71. doi:10.1053/j.seminoncol.2014.12.026

124. Michalek MT, Grant EP, Gramm C, Goldberg AL, Rock KL. A role for the ubiquitin-dependent proteolytic pathway in MHC class I-restricted antigen presentation. Nature (1993) 363(6429):552-4. doi:10.1038/363552a0

125. Banerjee S, Lu J, Cai Q, Sun Z, Jha HC, Robertson ES. EBNA3C augments Pim-1 mediated phosphorylation and degradation of p21 to promote B-cell proliferation. PLoS Pathog (2014) 10(8):e1004304.1. doi:10.1371/journal. ppat. 1004304

126. Kashuba E, Yurchenko M, Yenamandra SP, Snopok B, Isaguliants M, Szekely L, et al. EBV-encoded EBNA-6 binds and targets MRS18-2 to the nucleus, resulting in the disruption of pRb-E2F1 complexes. Proc Natl Acad Sci U S A (2008) 105(14):5489-94. doi:10.1073/pnas.0801053105

127. Hui KF, Tam KP, Chiang AKS. Therapeutic strategies against Epstein-Barr virus-associated cancers using proteasome inhibitors. Viruses (2017) 9(11):352. doi:10.3390/v9110352

128. Dong HY, Scadden DT, de Leval L, Tang Z, Isaacson PG, Harris NL. Plasmablastic lymphoma in HIV-positive patients: an aggressive EpsteinBarr virus-associated extramedullary plasmacytic neoplasm. Am JSurg Pathol (2005) 29(12):1633-41. doi:10.1097/01.pas.0000173023.02724.1f

129. Guerrero-Garcia TA, Mogollon RJ, Castillo JJ. Bortezomib in plasmablastic lymphoma: a glimpse of hope for a hard-to-treat disease. Leuk Res (2017) 62:12-6. doi:10.1016/j.leukres.2017.09.020
130. Michot JM, Bigenwald C, Champiat S, Collins M, Carbonnel F, Postel-Vinay $\mathrm{S}$, et al. Immune-related adverse events with immune checkpoint blockade: a comprehensive review. Eur J Cancer (2016) 54:139-48. doi:10.1016/j. ejca.2015.11.016

131. Armand P, Nagler A, Weller EA, Devine SM, Avigan DE, Chen YB, et al. Disabling immune tolerance by programmed death-1 blockade with pidilizumab after autologous hematopoietic stem-cell transplantation for diffuse large B-cell lymphoma: results of an international phase II trial. J Clin Oncol (2013) 31(33):4199-206. doi:10.1200/JCO.2012.48.3685

132. Hude I, Sasse S, Engert A, Brockelmann PJ. The emerging role of immune checkpoint inhibition in malignant lymphoma. Haematologica (2017) 102(1):30-42.1. doi:10.3324/haematol.2016.150656

133. Lozier J. More on hemophilia A induced by ipilimumab. N Engl J Med (2012) 366(3):280-1. doi:10.1056/NEJMc1113863

134. Delyon J, Mateus C, Lambert T. Hemophilia A induced by ipilimumab. N Engl J Med (2011) 365(18):1747-8. doi:10.1056/NEJMc1110923

135. Hoeller S, Tzankov A. Consideration of exposure to pharmacological agents helps to avoid diagnostic pitfalls in bone marrow histopathology. memo (2010) 3(3):132-5. doi:10.1007/s12254-010-0215-6

136. Saha A, O'Connor RS, Thangavelu G, Lovitch SB, Dandamudi DB, Wilson CB, et al. Programmed death ligand-1 expression on donor T cells drives graft-versushost disease lethality. J Clin Invest (2016) 126(7):2642-60. doi:10.1172/JCI85796

Conflict of Interest Statement: The authors declare that the research was conducted in the absence of any commercial or financial relationships that could be construed as a potential conflict of interest.

Copyright (c) 2018 Menter and Tzankov. This is an open-access article distributed under the terms of the Creative Commons Attribution License (CC BY). The use, distribution or reproduction in other forums is permitted, provided the original author(s) and the copyright owner are credited and that the original publication in this journal is cited, in accordance with accepted academic practice. No use, distribution or reproduction is permitted which does not comply with these terms. 